\title{
O JAPÃO EM TRADUÇÃO: TEXTOS BRASILEIROS ${ }^{1}$
}

\author{
Andrei Cunha
}

\section{Os primeiros cruzamentos culturais}

A história do Japão em tradução no Brasil pode ser contada de mais de uma forma. Neste texto, proponho inicialmente discutir algumas origens culturais, a partir de fatos e tendências verificáveis já desde o século XIX. Ao contrário da história da tradução de, digamos, textos franceses ou ingleses para o português do Brasil, considero que não é útil, no caso japonês, utilizar uma definição de tradução stricto sensu como critério de estabelecimento do corpus a ser discutido. Isso porque, se nos limitarmos aos textos traduzidos e publicados de maneira ortodoxa, a conclusão a que chegaremos é a mesma daqueles que formaram as ideologias que embasam a atividade de tradução no Brasil: a partir desse ponto de vista, a literatura japonesa traduzida e publicada aqui não passaria de uma anomalia, um mercado de nicho, uma exceção à norma sistêmica. Ora, eu gostaria de argumentar que a trajetória dos textos japoneses em suas encarnações brasileiras, antes de ser uma aberração, na verdade reflete a evolução histórica e cultural de nosso país, de maneira bastante lógica e cristalina. Para isso, no entanto, necessito começar recapitulando alguns fatos e livros que não pertencem necessariamente àquilo que uma história da tradução, definida de forma mais técnica, consideraria como sendo de sua alçada.

\footnotetext{
${ }^{1}$ Alguns trechos deste texto são retomados de trabalhos anteriores (cf. Cunha, 2011; 2013a; 2013c; 2014). Uma parte dos resultados foi apresentada oralmente no simpósio História e Historiografia da Tradução I - Brasil, coordenado por John Milton (USP) e Marcia A. P. Martins (PUC-Rio), por ocasião do XI Congresso Internacional da ABRAPT e V Congresso Internacional de Tradutores, realizado em Florianópolis, em 2013 (cf. Cunha, 2013b).
} 
Figura 1 - A Missão Iwakura (1871)

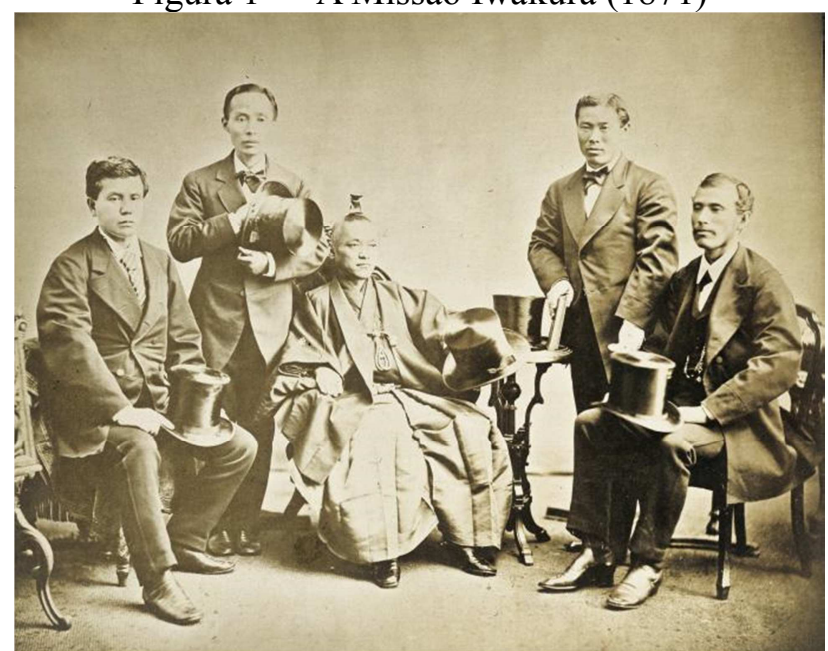

Iwakura Tomomi, o líder da missão, está em trajes japoneses tradicionais. Os outros membros da missão estão vestidos em modernos trajes ocidentais. Da esquerda para a direita: Kido Takayoshi, Yamaguchi Masuka, Iwakura Tomomi, Itô Hirobumi e Ôkubo Toshimichi. Todos pertenciam a importantes famílias samurai e seguiram posteriormente a carreira política. Fonte: Wikipédia

(2015).

Em 1871, um grupo de emissários diplomáticos japoneses partiu em viagem ao Ocidente. Conhecida posteriormente como "Missão Iwakura" (Figura 1), a empreitada tinha por líder o político e aristocrata Iwakura Tomomi (1825-1883). Os enviados levaram consigo, de volta ao Japão, uma infinidade de informações sobre o funcionamento dos países onde estiveram (dentre outros, os Estados Unidos, a Inglaterra, a Dinamarca, a Suécia, a Prússia, a França, a Rússia, a Itália e a Suíça). Nos anos seguintes, foi implementada uma série de reformas, em parte inspirada pelas observações desses viajantes. As inovações incluíam a criação de um exército moderno e de universidades baseadas principalmente no modelo alemão (muitas palavras japonesas relacionadas à Medicina, por exemplo, são de origem germânica); a adoção de um código civil com base no Napoleônico; uma constituição imperial que tinha traços russos e austro-húngaros; um parlamento que até hoje se chama Dieta, como o sueco; e conservatórios de música e academias de arte como as francesas. É dessa época também uma leva enorme de traduções literárias do alemão, do russo, do inglês e do francês, concomitante à criação do shôsetsu ${ }^{2}$, palavra originalmente chinesa, e que apenas no Japão designa os gêneros da narrativa de ficção nos moldes europeus (conto, folhetim, novela e romance).

\footnotetext{
${ }^{2}$ Shôsetsu (小説), “narrativa em prosa”.
} 
Uma das consequências mais espetaculares dessa onda de reformas foi um movimento chamado genbun itchi ${ }^{3}$, que culminou com a publicação, entre 1887 e 1889 , de Ukigumo, romance no estilo ocidental de Futabatei Shimei ${ }^{4}$. A obra foi a primeira a fazer uso apenas desse novo japonês, que, diferentemente da linguagem clássica associada até então ao campo do literário, permitia (na percepção desses autores) a escritura de romances "realistas modernos". O genbun itchi, talvez seja desnecessário dizer, baseava-se no "traducionês" usado por tradutores japoneses ao criarem suas versões de romances europeus (na verdade, muitos desses tradutores vieram a escrever, posteriormente, romances realistas). Essa é a forma que foi adotada, com algumas alterações, como norma culta do japonês escrito no século XX, e usada até hoje, não apenas na literatura.

Também no século XIX, no Brasil, os processos de tradução cultural e modernização foram ditados por uma combinação de circunstâncias locais e internacionais. Para as nações das Américas que se tornaram independentes de países europeus, "a língua não era um elemento de diferenciação entre a colônia e a metrópole [... e] todos tinham língua e ancestralidade em comum com aqueles contra quem estavam lutando" (Anderson, 1991, p.47). Maria Cristina Batalha (2001, p.117) descreve esse processo da seguinte maneira:

Após a independência do Brasil, em 1822, o desejo de marcar a diferença em relação a Portugal [...] levou-nos à rejeição da metrópole, resultando em uma nova forma de dependência, pois então foi o modelo francês que passou a ser adotado. [...] [A] França foi constante e gradativamente se tornando uma influência nociva no início do período republicano - um instrumento de alienação que fornecia os cânones da moda, das artes e da literatura $[\ldots]$.

A geração de intelectuais brasileiros anterior à de Maria Cristina Batalha ainda via a influência francesa como principalmente benéfica. Por exemplo, Antonio Candido afirma o seguinte:

[A] cultura francesa [...] se revelou mais aberta, menos ligada aos interesses das classes e dos grupos do que qualquer outra [...]. Consequentemente, é graças ao Francês que pudemos ver o mundo, que adquirimos o senso da História, que lemos os clássicos de todos os países, inclusive gregos e romanos. Certamente isto não é um simples acidente

\footnotetext{
${ }^{3}$ Genbun itchi (言文一致), “conformidade entre fala e escrita".

${ }^{4}$ Ukigumo (浮雲), "Nuvens Flutuantes". Futabatei Shimei, pseudônimo de Hasegawa Tatsunosuke (18641909). Autor de um influente Tratado Geral do Romance (1886). Tradutor da obra de Ivan Turgueniev e difusor do esperanto no Japão.
} 
histórico e esta situação só pôde se formar graças às características de versatilidade e universalidade que permitiram à cultura francesa uma posição única entre as demais. [... A] língua e cultura francesas ganharam na América Latina uma certa "aura", um prestígio que as coloca acima de outras impregnações culturais e étnicas. (Candido, 1977, p. 9-12)

Esse tipo de apologia da França não era raro até os anos 1980, e ainda tem consequências para a universidade brasileira, especialmente na área de humanas. No domínio da literatura e da tradução literária, a cultura francesa tem lugar central para o Brasil do século XIX. Até o final da Segunda Grande Guerra, o francês foi a principal via de intermediação entre as culturas não hegemônicas e a América Latina; foi por esse caminho indireto, por exemplo, que o haicai chegou ao Brasil (Franchetti, 2002). Paris era um centro criador de movimentos artísticos e literários (Casanova, 2002, p.42).

A sede de exotismo dos centros culturais europeus conheceu diferentes fases e ênfases. Após a abertura dos portos japoneses a estrangeiros, na década de 1860, o fluxo de bens e pessoas entre o Japão e a França, combinado a uma tradição orientalista europeia, deu início a uma febre de japonisme. No campo da literatura, a começar pela obra de Pierre Loti ${ }^{5}$, houve também reflexos dessa moda. O Japão, aos poucos, passou a representar "um outro Oriente", mais distante do que o "Oriente daqui [de lá]”, quase não comprometendo "nenhum país real" - um lugar meramente de fantasia, e que podia ser usado "sem a mínima pretensão de representar ou de analisar qualquer realidade, por menor que fosse" (Barthes, 1970, p. 9).

Um interessante paralelo poderia ser traçado entre o bric-à-brac orientalista e adocicado de Pierre Loti, um romântico tardio, e O Japão, de Aluísio de Azevedo, o primeiro texto de um brasileiro que conheceu a cultura japonesa in loco. Considerado a mais importante figura do naturalismo no Brasil, Aluísio de Azevedo foi também diplomata, e atuou como vice-cônsul no porto de Yokohama de 1897 a 1899 — ou seja, na década seguinte à da passagem do autor francês por Nagasáqui. $O$ Japão é um ensaio sobre a história japonesa, e reflete tanto ideias do orientalismo europeu e norte-americano, como uma versão ajaponesada do nacionalismo de Estado vigente à época em que seu autor visitou aquele país. No entanto, o texto tem uma riqueza e uma

\footnotetext{
${ }^{5}$ O escritor orientalista e oficial da marinha francesa Pierre Loti (1850-1923) se "casou" em 1885, no porto de Nagasáqui, com uma jovem japonesa de 18 anos de apelido "Madame Crisântemo", por meio de um contrato de um ano, renovável por mais um ano. Esse tipo de "casamento" era registrado na polícia e a moça podia, após a partida do estrangeiro, casar-se com um japonês. A experiência é reimaginada no romance Madame Chrysanthème (1887), que serviu como um dos hipotextos de Madama Butterfly, de Puccini (1904).
} 
complexidade de pontos de vista que se devem, em grande parte, ao fato de o livro ter sido escrito por alguém do Brasil, conforme argumenta Renato Ortiz (1997). Já está presente no pensamento de Aluísio de Azevedo uma reação comum em determinado perfil de intelectual brasileiro: a de identificação (a despeito das diferenças) entre Brasil e Japão.

De fato, as periódicas crises de identidade nacional do Brasil e do Japão têm em comum uma "angústia do nacional", um complexo de inferioridade, de "país que não funciona direito", com "as ideias fora do lugar", irracional e esquerdo, quando comparado à perfeição, à lógica, à pompa e, acima de tudo, ao poderio econômico e militar das grandes nações imperialistas. Essas dúvidas se manifestam por meio da literatura, tendo seguidamente o romance como gênero-teste - o romance, considerado como um "triunfo da cultura ocidental".

Não é à toa que podemos destacar as similaridades entre o narrador morto de Memórias Póstumas de Brás Cubas (1880) e o narrador felino de Eu Sou um Gato (19051906) ${ }^{6}$, de Natsume Sôseki. Ora, uma análise comparada das duas obras, daquelas ortodoxas que buscam relações de influência, cópia e original, poderia sustentar que o que os dois romances têm em comum é a ideia de um narrador extravagante - o que se deveria ao fato de tanto Machado de Assis como Natsume Sôseki terem sido grandes admiradores do Tristram Shandy (1759-1767), de Laurence Sterne. Ao mesmo tempo, tanto o Brasil do fim do século XIX, como o Japão do início do século XX, apesar de serem duas nações em fase de modernização, eram também sociedades tradicionais que se agarravam com especial capricho aos costumes que começavam a ver erodir, gerando um surplus de hipocrisia e brutalidade que apenas um sujeito alijado do mundo dos humanos vivos poderia destrinchar em paz. Não se pode perder de vista que tanto o defunto machadiano como o gato sôsekiano são narradores de obras consideradas como fundadoras do realismo em seus respectivos países: as traduções culturais, operadas pelo brasileiro e pelo japonês, passam por uma surrealização do paradigma de neutralidade realista, pondo a nu como artificial a ideia do narrador onisciente, algo que ficava oculto nos romances europeus dessa época.

\footnotetext{
${ }^{6}$ Eu Sou um Gato (吾輩は猫である, Wagahai wa Neko de aru), de Natsume Sôseki (1867-1916). Publicado no Brasil em 2008. Para as obras japonesas traduzidas no Brasil, vide referência ao final do artigo.
} 


\section{2, As quatro vertentes tradutórias}

A primeira publicação comercial de uma obra literária japonesa, traduzida para o português do Brasil, é de 1945 (Kato, 2006), quando a Editora Brasiliense publicou Rua sem $\mathrm{Sol}^{7}$, de Tokunaga Naoshi (Sunao) ${ }^{8}$, com tradução assinada por ninguém menos que Jorge Amado (Figura 2).

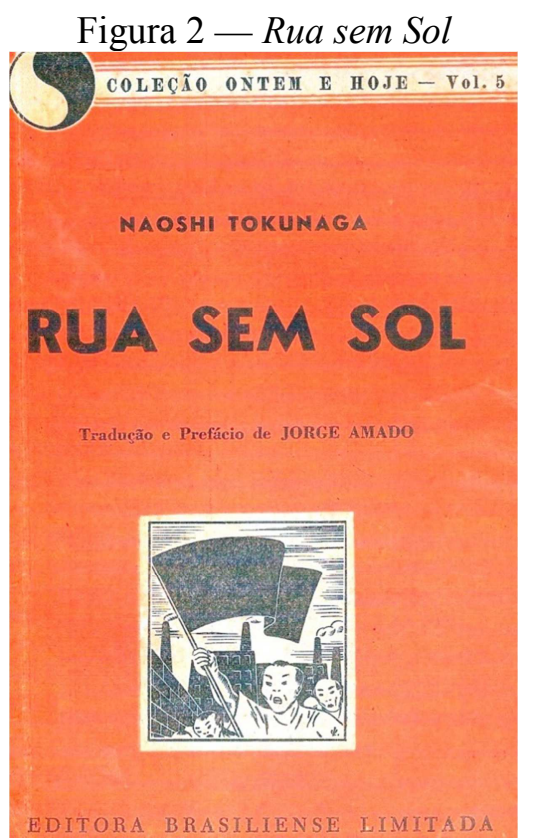

O primeiro livro de ficção japonesa editado no Brasil, Rua sem Sol, de Tokunaga Sunao (creditado como Naoshi), foi lançado pela Brasiliense em 1945. A tradução vinha assinada por Jorge Amado.

Na verdade, Jorge Amado não traduziu o livro — apenas emprestou seu nome (e prestígio de escritor) a uma coleção de textos de caráter socialista (Bottmann, 2013). Jorge Amado pertenceu ao Partido Comunista Brasileiro de 1931 a 1955, e era amigo de Arthur Neves e de Caio Prado Júnior, fundadores da Brasiliense. Tokunaga (1899-1958) foi um importante representante do movimento proletário no Japão. Ainda que essa publicação pareça ser um evento isolado, ela é uma consequência doméstica da

\footnotetext{
${ }^{7}$ Rua sem Sol (太陽のない街, Taiyô no nai Machi, edição japonesa de 1929). Não foi possível estabelecer em que língua estava o texto de partida dessa tradução.

${ }^{8}$ Seu nome é Sunao, ainda que às vezes erroneamente transcrito como Naoshi (maiores detalhes em Yoshida, 2003; Kato, 2006; e em Bottmann, 2013). As edições francesas do livro, de 1929 (editora Rieder) e de 1933 (Éditions Sociales Internationales), assim como a alemã, de 1929 (Internationaler Arbeiter-Verlag), também confundem o nome do autor, apresentando-o como Naoshi. O romance em japonês foi publicado no mesmo ano que a primeira edição francesa (1929), por uma editora chamada Nihon Puroretaria Sakka Sôsho (日本プロレタリア作家叢書, “Livraria Japonesa do Escritor Proletário").
} 
reconfiguração da ordem mundial do pós-guerra, que polarizou as ideologias e a produção cultural, seguindo um padrão de internacionalização (neste caso, o ideal de um "socialismo de todos os povos"). Temos aí a primeira vertente de textos traduzidos do japonês no Brasil: retraduções, por via do francês ou do inglês, de textos que adquirem sua importância no polissistema brasileiro devido a fatores extraliterários, tais como conjuntura política, imperialismo cultural, ou injunções de mercado.

O segundo livro de literatura japonesa traduzido e publicado no Brasil é de 1958. Árvores Irmãs é uma coletânea de sete contos, três dos quais foram traduzidos do inglês por Nelson Coelho e quatro diretamente do japonês por José Yamashiro ${ }^{9}$. Esse jornalista era um dos representantes da nova intelectualidade $n i k k e i^{10}$ - um grupo que atuava principalmente em São Paulo e Curitiba nos anos 1960 e 1970. Esses intelectuais bilíngues se acreditavam imbuídos de uma missão: apresentar a cultura japonesa ao Brasil e, a partir dessa intermediação, valorizar a posição social e o prestígio da comunidade nipo-brasileira — não se deve esquecer que, durante a Segunda Grande Guerra, os japoneses e descendentes de japoneses que viviam no Brasil sofreram toda sorte de perseguições políticas e culturais por parte do governo brasileiro.

A escolha dos contos de Árvores Irmãs e o processo de tradução estão em forte contraste com o caso de Rua sem Sol: eram textos de autores que, ainda que já considerados muito importantes domesticamente, na época ainda estavam em vias de consagração fora do Japão (alguns ainda vivos em 1958). A curadoria era, portanto, muito avançada para a época, e reunia nomes até então pouco conhecidos, mesmo na Europa e nos Estados Unidos (incluindo até Kawabata, dez anos antes de ganhar o prêmio Nobel). Devido ao fato de obedecer a uma lógica tradutória incomum, esse volume não fez tanto sucesso como outros, traduzidos na década seguinte, a partir do inglês e do francês.

Suzana Inokuchi (2011) descreve a vertente inaugurada por Árvores Irmãs como fruto de "iniciativas de tradução direta artesanal":

Todas essas iniciativas de tradução direta artesanal, oriundas da própria comunidade japonesa, visavam suprir a necessidade de visibilidade dessa mesma comunidade na realidade brasileira, antes mesmo que o mercado editorial nacional se desse conta do valor intrínseco da literatura japonesa, que vai muito além do âmbito do exótico e da diferença cultural. (Inokuchi, 2011)

\footnotetext{
${ }^{9}$ Os autores são: Akashi Kaijin, Hayashi Fumiko, Akutagawa Ryûnosuke e Kawabata Yasunari, traduzidos do japonês; e Niwa Fumio, Yokomitsu Riichi e Ozaki Kazuo, do inglês.

${ }^{10}$ Nikkei (日系), “descendente de japoneses".
} 
Ainda que fazendo uma concessão parcial à norma tradutória vigente à sua época (as traduções indiretas da língua inglesa), Árvores Irmãs já se enquadra em uma segunda vertente tradutória, pois inclui textos traduzidos diretamente do japonês, por um nipo-brasileiro que não era um tradutor profissional. Considero importante destacar, nessa vertente, uma pronunciada "consciência de cânone". Os autores e textos escolhidos são aqueles considerados, dentro do sistema literário japonês, como os melhores e mais importantes para o leitor japonês, sem considerações mercadológicas ou aparentes concessões ao gosto estrangeiro.

Nessa mesma vertente, outra importante coletânea de contos foi publicada em 1962: Maravilhas do Conto Japonês, com organização de Antônio Nojiri (Figura 3). Trata-se de um livro notável por muitos motivos. Em primeiro lugar, porque o volume pertence à prestigiosa coleção Maravilhas do Conto Universal, comercializada inicialmente entre 1957 e 1959 pela Editora Cultrix. A primeira edição da série, no entanto, não incluía nenhum tomo dedicado a países não ocidentais ${ }^{11}$. Foi apenas em 1962, numa edição ampliada, que foram incluídos os seguintes volumes: Maravilhas do Conto Chinês; Árabe; Japonês; Africano; e Indiano. A seleção e cronologia são bastante eloquentes: o "conto universal" vem da Europa e existe nas Américas; outras partes do mundo fazem parte dessa ideia de "universo" apenas de forma acessória. A orelha de Maravilhas do Conto Japonês (que podemos especular não ter sido escrita pelo organizador) tem o seguinte a dizer:

Conquanto praticamente ignorada do público ledor do Ocidente, a literatura japonesa é uma antiga e rica literatura, tão antiga e tão rica, talvez quanto algumas das principais literaturas nacionais da Europa. Nela encontramos, cultivados com um brilho e uma finura tipicamente nipônica, os mais diversos gêneros, desde romances-rios, como o Genji Monogatari, que tem sido comparado ao Dom Quixote e ao Moby Dick, até os haicais de Bashô, cuja magistral concisão seduz hoje nossos poetas de vanguarda, como seduziu ontem os amantes de bijuterias verbais.

A comparação implícita entre joia verdadeira e bijuteria soa especialmente desaforada; outra, entre Moby Dick e $O$ Romance do Genji, revela um total desconhecimento da obra de Murasaki Shikibu (a menos que seja o número de páginas

\footnotetext{
${ }^{11}$ Se considerarmos, claro, que a América Latina e a Rússia fazem parte do Ocidente, mas não caberia aqui discutir a questão. São estes os volumes da primeira edição: Maravilhas do Conto Alemão; Amoroso; de Aventuras; Bíblico; Brasileiro; Brasileiro Moderno; Espanhol; Fantástico; Feminino; de Ficção Científica; Francês; Hispano-Americano; Histórico; Humorístico; Inglês; Italiano; Mitológico; de Natal; Norte-Americano; Policial; Popular; Português; Russo; Universal.
} 
que esteja sendo considerado). Talvez fosse possível absolver o paratexto do pecado de apelar para um rosário de estereótipos, considerando que se trata de uma orelha, gênero com a função específica de chamar a atenção do comprador. Devemos também ter em conta que, em 1962, a visão que se tinha do Oriente no Brasil era ainda nublada pelo fantasma da Segunda Grande Guerra e pelas tensões, muito reais à época, da Guerra Fria. Por outro lado, a argumentação oferecida, de que a literatura japonesa, ignorada pelos ocidentais, é talvez tão rica e tão antiga quanto as "verdadeiras literaturas" (ou seja, os textos europeus), trai uma necessidade de se justificar a própria existência do Japão como cultura de valor - diga-se de passagem, à semelhança da percepção doméstica que existe, desde sempre, com relação à própria cultura brasileira.

Figura 3 - Maravilhas do Conto Japonês

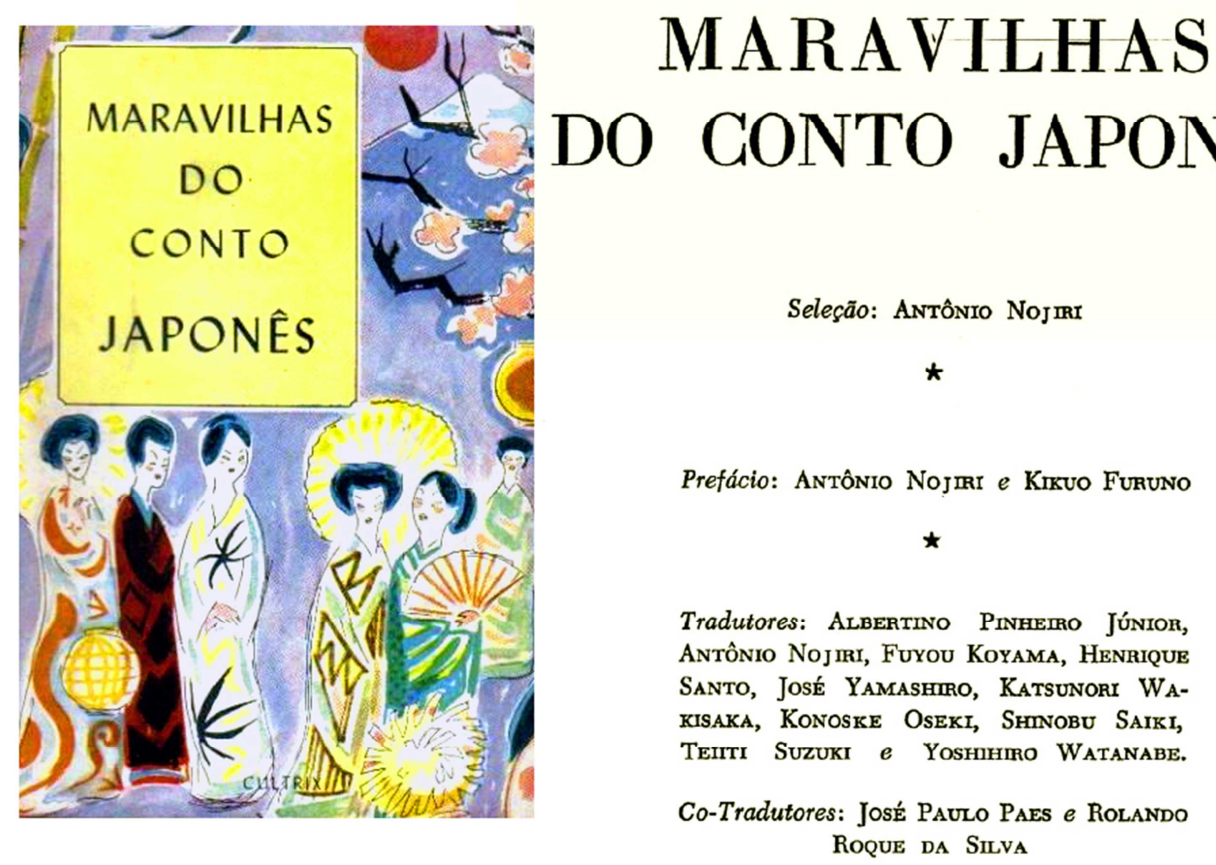

O rol de tradutores envolvidos na elaboração da antologia Maravilhas do Conto Japonês (1962) é um verdadeiro who's who da intelectualidade nipo-brasileira nos anos 1960.

Se a orelha é desafortunada, o conteúdo do livro é impressionante em seu escopo. O volume vem prefaciado com um texto de Nojiri, em coautoria com Kikuo Furuno, traçando um panorama da história da literatura japonesa, desde os mitos até a contemporaneidade. A coletânea em si é dividida em duas partes. A primeira, "Contos Tradicionais", cobre a evolução da literatura japonesa do século IX ao XVII. Incluídas nessa seção, estão passagens de livros-chave do cânone japonês - e os dois únicos 
trechos de Os Contos de Ise e de O Romance do Genji já publicados no país, até os dias de hoje, o que já bastaria para distinguir essa antologia como central na história da tradução de textos japoneses no Brasil. A segunda parte, "Contos Modernos", cobre os principais nomes da narrativa curta japonesa, do fim do século XIX até o pós-guerra. Esse período corresponde à fase em que os escritores japoneses adotaram o modelo ocidental de conto (tanpenshôsetsu ${ }^{12}$ ), em contraposição ao conto tradicional (monogatari ${ }^{13}$ ), da primeira parte do livro.

A publicação de Depois do Banquete, de Mishima Yukio, em 1968, é muitas vezes usada para demarcar o início de um novo período na história da tradução de obras do Japão no Brasil. Inokuchi define esta fase da seguinte maneira:

Até o início dos anos 90, a maioria das traduções era indireta, de idiomas como o inglês e o francês. Além disso, no caso, principalmente, das edições norte-americanas, o texto era cortado e apenas as partes consideradas mais adequadas para o público leitor desses países eram conservadas. Assim, o leitor brasileiro estava sujeito a receber uma obra incompleta e voltada para um leitor diverso. (Inokuchi, 2009)

Por outro lado, as edições dessa fase dão continuidade à vertente de retraduções (primeira vertente), iniciada em 1945 com Rua sem Sol, ainda que as motivações extraliterárias não sejam ostensivamente de ordem político-ideológica, e sim um reflexo de novas tendências do mercado de livros no Brasil da época ${ }^{14}$. Além da crescente importância do Japão como uma potência econômica no cenário internacional - as Olimpíadas de Tóquio, que tinham declaradamente o objetivo de divulgar ao mundo o chamado "milagre japonês", são de 1964 —, os motivos para o súbito interesse pela literatura japonesa no Brasil são provavelmente o grande sucesso de Mishima nos

\footnotetext{
${ }^{12}$ Tanpenshôsetsu (短編小説). Literalmente, “narrativa curta em prosa”; geralmente traduzido como "conto".

${ }^{13}$ Monogatari (物語). Literalmente, “contação de coisas"; geralmente traduzido como "história" ou "narrativa".

${ }^{14}$ Pode-se argumentar que Rua sem Sol e Depois do Banquete não pertenceriam à mesma vertente, haja vista que os motivos por trás das duas traduções seriam totalmente diferentes - político-ideológicos no primeiro caso, mercadológicos no segundo. No entanto, os dois casos possuem também muitas motivações e procedimentos em comum. Em primeiro lugar, são retraduções, feitas a partir de línguas hegemônicas, por tradutores contratados. Além disso, são títulos escolhidos por editores estrangeiros (europeus ou americanos) e não necessariamente os mais representativos de sua época ou movimento literário, no contexto japonês, nem os que seriam de maior interesse para um público leitor no contexto brasileiro. Por último, algo que considero de extrema importância, ambos são fruto da reconfiguração geopolítica e ideológica do mundo no século XX - oposição entre capitalismo e socialismo, e subsequente dominação soviética e americana (Guerra Fria). Em ambos os casos, a escolha dos autores e dos títulos foi como que "delegada" pelo editor brasileiro a seus colegas de países, culturas, línguas e blocos ideológicos hegemônicos.
} 
Estados Unidos e na Europa, assim como o Nobel de Literatura concedido a Kawabata Yasunari, naquele mesmo ano. Kawabata, que era também mentor de Mishima, foi o primeiro autor japonês a receber o prestigiado prêmio. Em 1969, dois livros de Kawabata são publicados no Brasil e, nos anos 1970, sete títulos de autores japoneses são traduzidos (incluindo Mishima, Kawabata, Endô Shûsaku e Matsumoto Seichô). Conforme destaca Venuti:

\begin{abstract}
Os editores americanos [...] estabeleceram um cânone para a ficção japonesa em inglês que, além de não ser representativo, se baseia em um estereótipo muito bem definido, que determinou as expectativas dos leitores [...]. Além disso, a formação de um estereótipo cultural construído a partir desse cânone se estendeu para além do inglês, já que as traduções inglesas de textos de ficção japonesa foram em geral traduzidas para outras línguas europeias durante o mesmo período. (Venuti, 1997, p.180-181)
\end{abstract}

A indústria cultural nacional, a partir dos anos 1960, vai se tornar cada vez mais globalizada - ainda assim, ela continua sendo o reflexo do mesmo campo literário internacional, em cujo contexto os dois maiores atores, no século XX e a partir de uma perspectiva brasileira, são os Estados Unidos e a França. Até os anos 1980, as literaturas de línguas não hegemônicas deviam passar preferencialmente pelo crivo de línguas hegemônicas; e a prioridade era dada ao tradutor cujo fazer era reconhecido pelo polissistema (o tradutor do inglês, devidamente "aculturado" às normas do mundo editorial), não ao falante nativo da língua exótica, tido como alijado dos fazeres e saberes da indústria de livros no Brasil. Por outro lado, já se pode perceber que, desde o final dos anos 1950, há uma tendência em sentido contrário, por parte da comunidade nikkei, no sentido de criar uma imagem cultural do Japão menos ligada ao exotismo e legitimada pela tradução direta e por escolhas de títulos em maior sintonia com o campo literário e com o cânone japonês.

Em 1985, como resultado do sucesso do filme de Paul Schrader (Mishima: uma vida em quatro capítulos), iniciou-se um fenômeno que pode ser chamado de "boom Mishima" no Brasil, com um total de nove livros traduzidos em quatro anos. O filme ganhou o prêmio de contribuição artística no Festival de Cannes e estreou no mesmo ano no Brasil, na Mostra Internacional de Cinema de São Paulo. No ano seguinte, foi distribuído comercialmente em todo o país. Mishima foi a primeira grande coprodução nipo-americana. Os produtores executivos foram Francis Ford Coppola e George Lucas. Para criar um panorama da vida e da obra do escritor, Schrader alterna a narrativa do último dia de vida de Mishima (culminando com o seu suicídio), algumas passagens 
apresentando os "fatos" de sua vida (em parte adaptadas, na verdade, do romance Confissões de uma Máscara, que é tratado pelo filme como fonte biográfica, não como ficção) e partes adaptadas de livros do autor - O Pavilhão Dourado, Kyôko no Ie $e^{15} \mathrm{e}$ Cavalo Selvagem.

A análise dos títulos adaptados torna clara a centralidade do filme (assim como a de Hollywood e a dos Estados Unidos) para o polissistema literário brasileiro. Dos quatro livros de autoria de Mishima aqui mencionados como fontes para os roteiristas, apenas Kyôko no Ie nunca foi traduzido para o português (Confissões, Pavilhão e Cavalo Selvagem foram traduzidos duas vezes cada um). A explicação é bastante simples: Kyôko no Ie também nunca foi traduzido para o inglês, e a edição prévia em inglês parece ser condição necessária para que a maioria dos livros japoneses conheçam uma tradução brasileira (mesmo quando traduzidos direto do japonês). Por outro lado, textos de Mishima que seriam de grande interesse para o leitor brasileiro - por exemplo, as crônicas escritas por ele sobre sua passagem no Brasil, incluídas em um livro que ele publicou em outubro de 1952, com o título de Aporon no Sakazuki ${ }^{16}$, ou ainda a peça de teatro Shiroari no $\mathrm{Su}^{17}$, que tem por cenário uma fazenda no interior de São Paulo nunca foram traduzidos para o português.

Nos anos 1990, houve poucas traduções de obras japonesas. Um fator a ser considerado é o lamentável estado da indústria cultural e da economia brasileira nesse período. A Brasiliense, uma das editoras que mais investira na tradução de obras japonesas, passava por sérias dificuldades, publicando um número reduzido de títulos. As grandes editoras perderam o interesse por literatura japonesa (Kato, 2006, p.52).

Durante essa fase, a vertente da tradução direta mostrou-se ativa, sobretudo na figura de professoras universitárias pertencentes à comunidade nikkei, como Geny Wakisaka, Luiza Nana Yoshida e Meiko Shimon. Por outro lado, talvez fosse mais conveniente considerar essa fase como uma nova vertente. A tradução direta já não pode ser chamada de "artesanal", pois essas tradutoras são todas japonesas, ou descendentes de japoneses, envolvidas profissionalmente, de uma maneira ou de outra, com a literatura e os fazeres tradutórios. Portanto, a terceira vertente tradutória consistiria em títulos traduzidos diretamente do japonês, por tradutores nipo-brasileiros com prática ou

\footnotetext{
${ }^{15}$ Kyôko no Ie (鏡子の家), “A Casa de Kyôko” (1959).

${ }^{16}$ Aporon no Sakazuki (アポロンの杯), “A Taça de Apolo” (1952).

${ }^{17}$ Shiroari no $\mathrm{Su}$ (白蟻の巣), “O Cupinzeiro” (1956).
} 
formação profissional na área de literatura ou tradução. Como o interesse comercial estava em segundo plano, a atuação desses tradutores (em grande maioria, mulheres) não reflete a crise econômica ou a cultural (alguns livros foram publicados por universidades; outros, financiados privadamente). Essas educadoras continuaram a produzir (editar, traduzir) livros de alta qualidade, formando também os tradutores que começariam a atuar na década seguinte. A sua presença em destaque na história da literatura japonesa em tradução no Brasil pode ser explicada em parte como sendo uma continuidade dos primeiros esforços tradutórios nipo-brasileiros, nos anos 1950 e 1960.

Nos anos 2000, ao contrário de Portugal, onde as traduções de textos de línguas não hegemônicas ainda são realizadas por intermédio do inglês ou do francês, no Brasil, as grandes editoras também começaram a investir em traduções diretas ${ }^{18}$. Pode-se dizer que isso resultou em uma fusão das vertentes anteriores: ainda que traduzidos diretamente do japonês, os novos títulos são muitas vezes escolhidos com um olho no mercado, e isso significa que um livro do Japão tem mais chance de ser traduzido no Brasil se ele antes foi bem-sucedido na França ou nos Estados Unidos. Assim, a quarta vertente tradutória consiste em livros publicados comercialmente, obedecendo à logica do mercado, traduzidos diretamente do japonês por tradutores profissionais com formação universitária específica, descendentes ou não de japoneses. O renovado interesse pela literatura japonesa vem na esteira do grande sucesso comercial de Musashi, de Yoshikawa Eiji (1999) e da obra de Murakami Haruki. Não se pode negar, também, que fatores extraliterários, como a grande voga recente da cultura popular japonesa no Brasil, foram determinantes para a maior visibilidade desses títulos.

\section{O que ainda falta fazer}

O número de obras literárias traduzidas do japonês ao português brasileiro está longe de refletir os estreitos laços históricos, étnicos, comerciais, culturais ou diplomáticos entre os dois países. O mesmo se pode dizer com relação à tradução de obras brasileiras no Japão, e os motivos são, na verdade, semelhantes - a começar pelo status não hegemônico das duas línguas nacionais. Nesse sentido, talvez se pudesse dizer que as trajetórias das duas literaturas em tradução têm mais afinidades circunstanciais do que a

\footnotetext{
${ }^{18}$ Dois exemplos de alta visibilidade são o Livro das Mil e uma Noites, de Mamede Mustafa Jarouche (o primeiro de quatro volumes foi publicado em 2005) e as obras de Dostoievski lançadas pela Editora 34 (um total de dezoito títulos, os primeiros dois publicados no ano 2000).
} 
brasileira teria com outras literaturas estrangeiras mais conhecidas no Brasil, como as de língua francesa, espanhola ou inglesa.

O propósito do presente texto foi lançar, na forma de questões para futuro desenvolvimento, algumas hipóteses sobre a presença da literatura japonesa no polissistema literário do Brasil. O corpus de textos brasileiros relacionados à tradução do japonês ainda precisa ser inventariado e discutido à luz da história da tradução como um todo no Brasil. Um levantamento parcial de Fabio Kato indica que entre 1945 e 2006 houve "setenta e nove edições de ficção japonesa lançadas no Brasil" (Kato, 2006, p. 6). O estudo de Kato, além de ser o primeiro (e, até o momento, um dos poucos) a abordar o tema, é extremamente útil e revela um rigor e pioneirismo notáveis; no entanto, seu recorte não inclui obras de poesia, nem de não ficção, e tampouco discute questões de intertextualidade ou relacionadas à literatura dos imigrantes. Além disso, o levantamento vai apenas até 2006 e, de lá para cá, a tradução de títulos japoneses continuou ativa. As tendências desse campo se modificaram nos anos 2010, com uma presença cada vez maior da literatura em quadrinhos — algo que também precisaria ser analisado.

Ainda está por ser elaborado um estudo que demonstre que esses aspectos e temas são complementares e interagem entre si. Desejo, finalmente, chamar a atenção para o fato de que não se pode pensar em tradução no Brasil sem levar em conta o sistema de interações mundiais e, principalmente, de que a presença da literatura japonesa no polissistema nacional não é um caso isolado, uma exceção ou uma anomalia. Muito pelo contrário: a forma como ela se instaura nesse contexto está em calma conformidade com os desenvolvimentos históricos, culturais e estéticos de cada época, tanto dentro como fora do Brasil.

\section{Referências}

ANDERSON, B. Imagined Communities. Londres: Verso, 1991.

BARTHES, R. L'empire des signes. Genebra: Skira, 1970.

BATALHA, M.C. The Place of Foreign Literature in the Brazilian Literary System. Tradução para o inglês de John MILTON. In: MILTON, J. (Org.). Emerging Views on Translation History in Brazil, CROP (Special Edition), v. 6, 2001, p. 109-128.

BOtTMAnN, D. Jorge Amado, Tradutor (I). Não Gosto de Plágio. 16 fev. 2013. Disponível em: 
<http://naogostodeplagio.blogspot.com.br/2013/02/jorge-amado-tradutor.html>. Acesso em: 30 mai. 2014.

CANDIDO, A. [Assinando como Antônio Cândido de Mello e Souza]. O Francês Instrumento de Desenvolvimento. Traduzido do francês por Diva B. Damato. In: CANDIDO, A.; CARONI, I.; LAUNAY, M. O Francês Instrumental: a experiência da Universidade de São Paulo. São Paulo: Hemus, 1977. p. 9-17.

CASANOVA, P. A República Mundial das Letras. Tradução de Marina Appenzeller. São Paulo: Estação Liberdade, 2002.

FRANCHETTI, P. O haicai no Brasil. Poesia Sempre, Rio de Janeiro, Biblioteca Nacional, n.17, p.23-40, 2002.

INOKUCHI, S. Considerações sobre tradução de literatura japonesa. Memai: Letras e artes japonesas. 30 dez. 2009. Disponível em: http://www.memai.com.br/2009/12/por-tras-da-traducao-de-literatura-japonesa/. Acesso em: 08 fev. 2015.

INOKUCHI, S. Tradução artesanal. Memai: Letras e artes japonesas. 30 dez. 2011. Disponível em: <http://www.memai.com.br/2011/01/traducao-direta-artesanal-uma-iniciativa-da-c omunidade-japonesa/>. Acesso em: 08 fev. 2015.

KATO, F. Edições brasileiras de ficção japonesa. São Paulo, 2006. 195 f. Trabalho de Conclusão de Curso. Escola de Comunicações e Artes, Universidade de São Paulo. MISHIMA, Y. Cavalo Selvagem. Tradução de Isa Mara Lando, com revisão de Meiko Shimon. São Paulo: Benvirá/Saraiva, 2014.

MISHIMA, Y. Cavalo Selvagem. Tradução de Isa Mara Lando. São Paulo: Brasiliense, 1987.

MISHIMA, Y. Confissões de uma máscara. Tradução de Jaqueline Nabeta. São Paulo: Companhia das Letras, 2004.

MISHIMA, Y. Confissões de uma máscara. Tradução de Manoel Paulo Ferreira. São Paulo: Vertente, 1976.

MISHIMA, Y. Depois do Banquete. Tradução de Vera Pedrosa. Rio de Janeiro: Edinova, 1968.

MISHIMA, Y. O Pavilhão Dourado. Tradução de Shintaro Hayashi. São Paulo: Companhia das Letras, 2010. 
MISHIMA, Y. O Templo do Pavilhão Dourado. Tradução de Eliana Sabino. Rio de Janeiro: Rocco, 1988.

MISHIMA: a life in four chapters. Direção: Paul Schrader. Produção: Francis Ford Coppola e George Lucas. Estados Unidos/Japão: Zoetrope, 1985.

NATSUME, S. Eu sou um gato. Tradução de Jefferson Teixeira. São Paulo: Estação Liberdade, 2008.

NOJIRI, A. (Org.). Maravilhas do Conto Japonês. Traduções de Albertino Pinheiro Júnior, Antônio Nojiri, Fuyou Koyama, Henrique Santo, José Yamashiro, Katsunori Wakisaka, Konoske Oseki, Shinobu Saiki, Teiiti Suzuki, Yoshihiro Watanabe, José Paulo Paes e Rolando Roque Da Silva. São Paulo: Cultrix, 1962.

ORTIZ, R. Aluísio de Azevedo e o Japão: uma apreciação crítica. Tempo Social, n. 9, v. 2, p.79-95, out. 1997.

TOKUnAGA, N. Rua sem Sol. Tradução atribuída a Jorge Amado. São Paulo: Brasiliense, 1945.

VENUTI, L. A tradução e a formação de identidades culturais. Tradução de Lenita Esteves. In: SIGNORINI, I. (Org.). Lingua(gem) e Identidade: elementos para uma discussão do campo aplicado. Campinas: Mercado das Letras, 1997. p. 173-200.

YAMASHIRO, J.; COELHO, N. (Org., Trad.). Árvores Irmãs. São Paulo: Clube do Livro, 1958.

YOSHIDA, L. Literatura japonesa em língua portuguesa. Made in Japan, v. 74, p. 62, 2003.

YOSHIKAWA, E. Musashi, v. I, II. Tradução e notas de Leiko Gotoda. São Paulo: Estação Liberdade, 1999. 